\title{
Bazedoxifene improves renal function and increases renal phosphate excretion in patients with postmenopausal osteoporosis
}

Hideki Masaki, Yasuo Imanishi, Hiroshi Naka, Yuki Nagata, Masafumi Kurajoh, Katsuhito Mori, Masanori Emoto, Takami Miki \& Masaaki Inaba

\begin{tabular}{|c|l|}
\hline Citation & Journal of Bone and Mineral Metabolism. 38(3); 405-411 \\
\hline Issue Date & 2020-01-02 \\
\hline Type & Journal Article \\
\hline Textversion & Author \\
\hline \multirow{2}{*}{ Rights } & $\begin{array}{l}\text { This is a post-peer-review, pre-copyedit version of an article published in Journal } \\
\text { of Bone and Mineral Metabolism. The final authenticated version is available } \\
\text { online at: https://doi.org/10.1007/s00774-019-01073-1. } \\
\text { See Springer Nature terms of use. } \\
\text { https://www.springer.com/gp/open-access/publication-policies/aam-terms-of-use. }\end{array}$ \\
\hline DOI & 10.1007/s00774-019-01073-1 \\
\hline
\end{tabular}

\author{
Self-Archiving by Author(s) \\ Placed on: Osaka City University
}

Masaki, H., Imanishi, Y., Naka, H. et al. Bazedoxifene improves renal function and increases renal phosphate excretion in patients with postmenopausal osteoporosis. Journal of Bone and Mineral Metabolism. 38, 405-411 (2020). Doi:10.1007/s00774-019-01073-1 


\section{Original article}

Bazedoxifene improves renal function and increases renal phosphate excretion in patients with postmenopausal osteoporosis

Hideki Masaki ${ }^{1}$, Yasuo Imanishi ${ }^{1}$, Hiroshi Naka ${ }^{2}$, Yuki Nagata ${ }^{1}$, Masafumi Kurajoh $^{1}$, Katsuhito Mori ${ }^{3}$, Masanori Emoto ${ }^{1}$, Takami Miki ${ }^{4}$, Masaaki Inaba ${ }^{1}$

${ }^{1}$ Department of Metabolism, Endocrinology and Molecular Medicine, Osaka City

University Graduate School of Medicine, Osaka, Japan

${ }^{2}$ Kousai-in hospital, Osaka, Japan

${ }^{3}$ Department of Nephrology, Osaka City University Graduate School of Medicine, Osaka, Japan

${ }^{4}$ Izumi Otsu Municipal Hospital, Osaka, Japan

Address all correspondence to: Yasuo Imanishi, M.D., Ph.D.

Department of Metabolism, Endocrinology and Molecular Medicine, Osaka City

University Graduate School of Medicine, 1-4-3, Asahi-machi, Abeno-ku, Osaka 545- 
8585, Japan.

Tel: +81-6-6645-3806; Fax: +81-6-6645-3808; E-mail: imanishi@med.osaka-cu.ac.jp ORCID: 0000-0002-9077-2631 


\section{Abstract}

Because aging is a predictor of renal insufficiency in the general population, renal function is a concern in postmenopausal patients undergoing treatment for osteoporosis. Although high serum phosphate concentration is a predictor of renal insufficiency, the effect of selective estrogen receptor modulator (SERM) on renal function and phosphate homeostasis remains to be established. We administered $20 \mathrm{mg}$ /day bazedoxifene to 48 postmenopausal osteoporotic women who had been taking alfacalcidol for $\geq 6$ months, and assessed lumbar spine bone mineral density (LS-BMD), renal function (by calculating estimated glomerular filtration rate [eGFRcys] using serum cystatin-C levels [range: $38.0-98.2 \mathrm{~mL} / \mathrm{min} / 1.73 \mathrm{~m}^{2}$ ]), and phosphate homeostasis. LS-BMD was significantly higher 6 months after the initiation of bazedoxifene administration. eGFRcys had increased by 3 months after initiation and was stable until 12 months. Serum phosphate gradually decreased after initiation, reaching statistical significance at 6 months. The changes in serum phosphate were also significant when the maximum tubular reabsorption rate of phosphate was normalized to glomerular filtration rate (TmP/GFR), indicating that bazedoxifene treatment reduces serum phosphate by increasing the urinary excretion of phosphate. The change in eGFRcys after the initiation 
of bazedoxifene was significantly negatively correlated with the change in serum phosphate, suggesting that a reduction in serum phosphate improves renal function. In conclusion, bazedoxifene improves renal function, possibly by increasing renal phosphate excretion, in postmenopausal osteoporotic women without severe renal insufficiency.

Key words: osteoporosis, chronic kidney disease (CKD), bazedoxifene, estimated glomerular filtration rate (eGFRcys), phosphate, maximum tubular reabsorption rate of phosphate to glomerular filtration rate (TmP/GFR) 


\section{Introduction}

Aging is a predictor of both chronic kidney disease (CKD) [1-3] and osteoporosis.

$[1,4]$ Because CKD is a comorbidity that increases the risk of osteoporotic fracture, $[5,6]$

kidney function should be considered during the management of osteoporosis.

Serum phosphate is well-known predictor of clinical outcomes, such as all-cause and cardiovascular mortality, in advanced CKD, including end-stage renal disease.[7, 8] Even in individuals with normal kidney function, hyperphosphatemia can predispose toward cardiovascular diseases, such as coronary artery disease.[9-11] Teriparatide treatment reduces intima-media thickness of the carotid artery wall, in part by reducing serum phosphate concentration, secondary to renal phosphate wasting, implying that serum phosphate has deleterious effects on vessels.[12] Furthermore, cross-sectional and longitudinal studies have shown associations between serum phosphate and renal impairment in CKD patients not on dialysis, $[13,14]$ and in the general population, high serum phosphate has also been reported to be associated with renal impairment.[15]

Bazedoxifene, a selective estrogen receptor modulator (SERM), has sustained efficacy in preventing new vertebral fractures in postmenopausal women with osteoporosis and in preventing non-vertebral fractures in higher-risk women.[16] 
Bazedoxifene,[17] and another SERM, raloxifene,[18] have also been reported to have consistent effects on bone mineral density and fracture prevention. However, it is unknown whether SERMs have a renoprotective effect.

In the present study, we aimed to evaluate the renoprotective effect of bazedoxifene and the relationship between any renoprotective effect and phosphate homeostasis in postmenopausal osteoporotic women without moderate or severe renal impairment.

\section{Materials and Methods}

Study design and participants

This study was a description research and did not have non-treatment control.

We studied 48 postmenopausal osteoporotic women who had been taking alfacalcidol for $>6$ months, in whom we initiated the administration of $20 \mathrm{mg}$ /day bazedoxifene, while maintaining the same dose of alfacalcidol. The participants were recruited between November 2013 and September 2016 at the Osaka City University Hospital, and were followed up for 1 year after the initiation of bazedoxifene. All the participants were capable of visiting the hospital independently. Patients with the following comorbidities 
were excluded from the study: severe renal insufficiency, defined as an estimated glomerular filtration rate (eGFRcys) $<30 \mathrm{~mL} / \mathrm{min} / 1.73 \mathrm{~m}^{2}$; metabolic bone diseases, such as osteomalacia or Paget's disease of the bone; endocrine disorders, such as primary hyperparathyroidism or hyperthyroidism; poorly controlled diabetes mellitus; rheumatoid arthritis; alcohol abuse; or metastatic bone tumor.

\section{Ethics}

Informed consent was obtained from all individual participants included in the study. The study was approved by the Osaka City University Graduate School of Medicine Ethics Committee (approval \#1776) and was conducted in accordance with the principles of the Declaration of Helsinki.

\section{Biochemical parameters}

Serum samples and second voided urine samples were collected in the morning after an overnight fast. Serum calcium $(\mathrm{Ca})$, phosphate, and creatinine $(\mathrm{Cr})$ concentrations were determined by enzymatic methods using a Hitachi 7450 autoanalyzer (Hitachi Co., Tokyo, Japan). The ratio of the maximum tubular reabsorption rate of phosphate to glomerular filtration rate $(\mathrm{TmP} / \mathrm{GFR})$ is an indicator of urinary phosphate reabsorption, 
and was calculated using serum and second voided urine data, as previously described.[20] Serum whole parathyroid hormone (wPTH) was measured using an immunoradiometric assay (Scantibodies Laboratory, Inc., Santee, CA, USA) [21]. A radioimmunoassay (RIA) was used to measure serum $1,25(\mathrm{OH})_{2} \mathrm{D}$ concentration (Immunodiagnostic Systems, England). The 25-hydroxy-vitamin D 125I RIA Kit (DiaSorin S. P. A, Saluggia, Italy), which is based on the RIA 2 antibody method, was used to measure serum 25-hydroxyvitamin D concentration. Serum fibroblast growth factor (intact FGF23) levels were measured using the Human FGF-23 ELISA Kit (Kinos, Tokyo, Japan).

Serum cystatin-C level was measured using latex agglutination tests. To assess renal function, eGFRcys was calculated using the equation [19]: eGFRcys ( $\mathrm{mL} / \mathrm{min} / 1.73$ $\left.\mathrm{m}^{2}\right)=\left(104 \times\right.$ serum cystatin- $\left.\mathrm{C}^{-1.019} \times 0.996^{\text {age }} \times 0.929\right)-8$ for women. To avoid the effects of interassay variance, serum samples for the measurement of cystatin-C was stored at $-30 \mathrm{C}$ and assayed in the same assay run.

\section{Bone mineral density measurements}

Lumbar spine (LS)-bone mineral density (BMD), femoral neck (FN)-BMD, and total hip (TH)-BMD were assessed by dual X-ray absorptiometry (DXA) using the QDR 
4500A DXA system (Hologic Inc., Marlborough, MA, USA), both at baseline and after 6 and 12 months of bazedoxifene treatment. Any regions showing degenerative changes and/or vertebral fractures were excluded from the LS-BMD. Vertebral fractures were assessed using a semi-quantitative method [22]. Participant measurements were included in the study data analysis if there were at least two measurable LSs in the L2-4 region.

\section{Statistical analysis}

Data are expressed as the number (\%), mean \pm standard deviation (SD), or median (interquartile range), as appropriate. The mean differences in LS-BMD, eGFRcys, and serum phosphate from baseline following bazedoxifene administration were compared using one-way repeated measures analysis of variance (ANOVA), followed by Dunnett's test. The correlations between the changes in serum phosphate ( $\Delta$ phosphate) and in eGFRcys ( $\triangle$ eGFRcys) after the first 3 months of bazedoxifene administration were determined using simple regression.

$P<0.05$ was considered to represent statistical significance. All statistical analyses were performed using JMP software, version 11.2.0 (SAS Institute, Cary, NC, USA). 


\section{Results}

\section{Participants and treatments}

Of the 48 participants enrolled, all were postmenopausal women and all were followed for at least 6 months after their first dose of bazedoxifene. All the participants completed this 6 month period of therapy without reporting any adverse effects.

The baseline serum parameters for the participants are shown in Table 1. Renal function was distributed over a wide range (eGFRcys: $38.0-98.2 \mathrm{~mL} / \mathrm{min} / 1.73 \mathrm{~m}^{2}$ ), but none of the participants had severe renal insufficiency (eGFRcys: $<30 \mathrm{~mL} / \mathrm{min} / 1.73 \mathrm{~m}^{2}$ ). No new fractures, including of the vertebrae, were identified during the study period. Blood pressure, fasting blood glucose concentration, and body mass index (BMI) were all stable during the study period.

Changes in clinical parameters following bazedoxifene treatment

LS-BMD had significantly increased at 6 months $\left(0.691 \pm 0.079 \mathrm{~g} / \mathrm{cm}^{2}\right)$ and was stable until 12 months $\left(0.690 \pm 0.081 \mathrm{~g} / \mathrm{cm}^{2}\right)$ compared to before the initiation of bazedoxifene $\left(0.684 \pm 0.076 \mathrm{~g} / \mathrm{cm}^{2}\right)$ (Fig. 1), while the eGFRcys had significantly increased by 3 months and was stable until 12 months (Fig. 2). Serum phosphate and 
TmP/GFR decreased gradually and the reduction became significant from 6 months after the initiation of bazedoxifene (Fig. 3). Serum wPTH significantly increased at 6 month (Fig. 4). Serum intact FGF23 significantly decreased from 3 months (Fig. 5).

Linear regression analysis of the relationship between phosphate homeostasis and eGFRcys

Baseline serum phosphate significantly correlated with TmP/GFR $(r=0.710$, $p<0.0001)$. The changes in serum phosphate also significantly correlated with those in TmP/GFR during the 6 months following the first bazedoxifene dose $(\mathrm{r}=0.836, p=0.0001)$. Furthermore, the changes in eGFRcys after the initiation of bazedoxifene ( $\Delta \mathrm{eGFRcys)}$ exhibited a significant negative correlation with those of serum phosphate concentration at 1 month $(\mathrm{r}=-0.392, \mathrm{p}=0.0058)$ and 3 months $(\mathrm{r}=-0.287, p=0.0479)$ (Fig. 6). However, the changes in eGFRcys after the initiation of bazedoxifene did not correlate with the changes in BMD or serum Ca concentration. No relationship was observed between the changes in LS-BMD and phosphate homeostasis. In addition, no significant relationships were observed between the changes in serum phosphate levels and those in wPTH or intact FGF23. 


\section{Discussion}

In this 12 month prospective study, an improvement in renal function was identified after the initiation of bazedoxifene in postmenopausal osteoporotic patients undergoing alfacalcidol therapy. These improvements in renal function, shown using eGFRcys, significantly correlated with the decreases in serum phosphate concentration, suggesting that the beneficial effect of bazedoxifene on renal function may be exerted, at least in part, via a change in phosphate homeostasis.

Bazedoxifene increased LS-BMD in patients who were already being treated with alfacalcidol over the 12 months of the study. This finding is consistent with the previous demonstration that the use of a combination of raloxifene and alfacalcidol is associated with larger increases in LS-BMD than the use of raloxifene alone.[23] Furthermore, in a randomized three-arm trial, a combination of raloxifene and alfacalcidol increased LS-BMD more than either raloxifene or alfacalcidol alone.[24] In addition, a combination of raloxifene and a vitamin D analogue, eldecalcitol, improved BMD and bone mechanical strength more effectively than each drug alone in ovariectomized rats.[25] However, although combination therapy with raloxifene and active vitamin D have been shown to be effective at increasing LS-BMD, this is the first 
report that the use of another SERM, bazedoxifene, is associated with greater LS-BMD gain when used alongside alfacalcidol in postmenopausal women.

A renoprotective effect of raloxifene was shown by post-hoc analyses of a double-blinded, placebo-controlled, randomized clinical trial of 7,705 postmenopausal women with osteoporosis,[26] and this effect has been shown to involve a reduction in the rate of progression of albuminuria.[27] Specifically, raloxifene attenuates proteinuriainduced renal tubular damage by modulating mitochondrial oxidative status in glomerulonephritic mice.[28] Other SERMs, such as tamoxifen, have also been reported to have a renoprotective effect.[29] In a rat model of hypertensive nephrosclerosis, tamoxifen prevented glomerulosclerosis and interstitial fibrosis by inhibiting transforming growth factor (TGF)- $\beta 1$ and plasminogen activator inhibitor-1. In this study, bazedoxifene significantly increased eGFRcys in the subjects, in contrast with the previously reported age-related eGFRcys decline.[30, 31] This study is the first to show that bazedoxifene not only prevents renal insufficiency, but actually improves renal function.

Phosphate homeostasis involves fluxes in the intestine, kidney, and bone, and the renal handling of phosphate (TmP/GFR) is a major determinant of the serum phosphate concentration.[12] In this study, baseline serum phosphate concentration 
significantly correlated with TmP/GFR, as did the changes in serum phosphate concentration and the changes in TmP/GFR, during the 6 months of bazedoxifene treatment, without any changes in serum Ca or wPTH. Although alfacalcidol promotes the absorption of phosphate, as well as $\mathrm{Ca}$, in the intestine, the doses administered were consistent during the present study. In this study, TmP/GFR was also shown to be a major determinant of serum phosphate concentration, as described previously.[12] This is the first report that bazedoxifene reduces serum phosphate and also reduces TmP/GFR. A reduction in serum phosphate has also been reported in healthy men taking raloxifene,[32] which reduces TmP/GFR without changing serum PTH and renal function. In this study, wPTH was elevated by bazedoxifene and elevated wPTH might decrease serum phosphate levels by the increment of renal phosphate excretion, however, no significant relationship between wPTH and phosphate metabolism. Another phosphaturic hormone FGF23 decreased. The roles of wPTH and intact FGF23 in the decrement of serum phosphate levels were not clear in this study. An increase in estradiol has been shown to be associated with a decrease in TmP/GFR,[33] and hormone replacement therapy in postmenopausal women reduces TmP/GFR,[34] implying a significant role for the estrogen receptor in renal phosphate handling.

In CKD patients, $[13,14]$ high serum phosphate predicts progression towards 
end-stage renal disease; therefore, phosphate-lowering therapy, such as the use of phosphate binders, is recommended.[35] In the general population[15, 36] and in a systematic review of previous studies,[37] serum phosphate concentration has also been shown to predict the progression of CKD. However, little is known regarding the effect of phosphate-lowering treatment on renal function in populations without CKD. In the present study, the reductions in serum phosphate and the improvements in eGFRcys were strongly correlated, suggesting that the reduction in serum phosphate induced by bazedoxifene is at least partially responsible for the improvement in renal function.

The principal limitations of the present study were that it was not a randomized controlled trial and appropriate untreated controls were not included. A prospective randomized controlled trial is needed for verification. The small sample seize of Japanese patients were also limitations of this study, because selection bias may exist and the findings of this study are not able to extend to other ethnicities. Another limitation is that only a small number of osteoporotic patients complicated CKD. So the renoprotective effect of bazedoxifene is limited to only those without CKD. A further study is necessary to elucidate the effect of bazedoxifene on those with CKD. However, bazedoxifene therapy improved renal function for 12 months, suggesting that its effects were clinically significant. 
In conclusion, bazedoxifene improves LS-BMD and eGFRcys, suggesting that bazedoxifene ameliorates both osteoporosis and improves renal function. Furthermore, these improvements in renal function were associated with reductions in serum phosphate, which has well-known deleterious effects on kidney function.

\section{Author contributions}

HM contributed to the acquisition, analysis, and interpretation of the data. YI, HN, and TM contributed to the conception and design of the study. YI, HN, YN, MK, KM, ME, TM, and MI contributed to the acquisition of the data. HM takes responsibility for the integrity of the data analysis. All authors participated in drafting or revising the manuscript and approved the final version of the manuscript for submission.

\section{Conflicts of interest}

TM and MI has received grant support and lecture fees from Pfizer Japan Inc.

YI, EM, TM, and MI have received lecture fees from Pfizer Japan Inc.

$\mathrm{HM}, \mathrm{HN}, \mathrm{YN}$, and KM have no conflicts of interest. 


\section{References}

1. Klawansky S, Komaroff E, Cavanaugh PF, Jr., Mitchell DY, Gordon MJ, Connelly JE, Ross SD (2003) Relationship between age, renal function and bone mineral density in the US population. Osteoporos Int 14:570-576

2. Hill NR, Fatoba ST, Oke JL, Hirst JA, O'Callaghan CA, Lasserson DS, Hobbs FD (2016) Global Prevalence of Chronic Kidney Disease - A Systematic Review and MetaAnalysis. PLoS One 11:e0158765

3. Gasparini A, Evans M, Coresh J, Grams ME, Norin O, Qureshi AR, Runesson B, Barany P, Arnlov J, Jernberg T, Wettermark B, Elinder CG, Carrero JJ (2016) Prevalence and recognition of chronic kidney disease in Stockholm healthcare. Nephrol Dial Transplant 31:2086-2094

4. Yoshimura N, Muraki S, Oka H, Mabuchi A, En-Yo Y, Yoshida M, Saika A, Yoshida H, Suzuki T, Yamamoto S, Ishibashi H, Kawaguchi H, Nakamura K, Akune T (2009) Prevalence of knee osteoarthritis, lumbar spondylosis, and osteoporosis in Japanese men and women: the research on osteoarthritis/osteoporosis against disability study. J Bone Miner Metab 27:620-628

5. Hippisley-Cox J, Coupland C (2012) Derivation and validation of updated QFracture algorithm to predict risk of osteoporotic fracture in primary care in the United Kingdom: prospective open cohort study. BMJ 344:e3427

6. Fried LF, Biggs ML, Shlipak MG, Seliger S, Kestenbaum B, Stehman-Breen C, Sarnak M, Siscovick D, Harris T, Cauley J, Newman AB, Robbins J (2007) Association of kidney function with incident hip fracture in older adults. J Am Soc Nephrol $18: 282-286$

7. Covic A, Kothawala P, Bernal M, Robbins S, Chalian A, Goldsmith D (2009) Systematic review of the evidence underlying the association between mineral metabolism disturbances and risk of all-cause mortality, cardiovascular mortality and cardiovascular events in chronic kidney disease. Nephrol Dial Transplant 24:1506-1523

8. Kanbay M, Goldsmith D, Akcay A, Covic A (2009) Phosphate - the silent stealthy cardiorenal culprit in all stages of chronic kidney disease: a systematic review. Blood Purif 27:220-230

9. Tonelli M, Sacks F, Pfeffer M, Gao Z, Curhan G, Cholesterol, Recurrent Events Trial I (2005) Relation between serum phosphate level and cardiovascular event rate in 
people with coronary disease. Circulation 112:2627-2633

10. Dhingra R, Sullivan LM, Fox CS, Wang TJ, D'Agostino RB, Sr., Gaziano JM, Vasan RS (2007) Relations of serum phosphorus and calcium levels to the incidence of cardiovascular disease in the community. Arch Intern Med 167:879-885

11. Cancela AL, Santos RD, Titan SM, Goldenstein PT, Rochitte CE, Lemos PA, dos Reis LM, Graciolli FG, Jorgetti V, Moyses RM (2012) Phosphorus is associated with coronary artery disease in patients with preserved renal function. PLoS One 7:e36883

12. Yoda M, Imanishi Y, Nagata Y, Ohara M, Yoda K, Yamada S, Mori K, Inaba M (2015) Teriparatide Therapy Reduces Serum Phosphate and Intima-Media Thickness at the Carotid Wall Artery in Patients with Osteoporosis. Calcif Tissue Int 97:32-39

13. Landray MJ, Emberson JR, Blackwell L, Dasgupta T, Zakeri R, Morgan MD, Ferro CJ, Vickery S, Ayrton P, Nair D, Dalton RN, Lamb EJ, Baigent C, Townend JN, Wheeler DC (2010) Prediction of ESRD and death among people with CKD: the Chronic Renal Impairment in Birmingham (CRIB) prospective cohort study. Am J Kidney Dis 56:1082-1094

14. Chue CD, Edwards NC, Davis LJ, Steeds RP, Townend JN, Ferro CJ (2011) Serum phosphate but not pulse wave velocity predicts decline in renal function in patients with early chronic kidney disease. Nephrol Dial Transplant 26:2576-2582

15. O'Seaghdha CM, Hwang SJ, Muntner P, Melamed ML, Fox CS (2011) Serum phosphorus predicts incident chronic kidney disease and end-stage renal disease. Nephrol Dial Transplant 26:2885-2890

16. Silverman SL, Chines AA, Kendler DL, Kung AW, Teglbjaerg CS, Felsenberg D, Mairon N, Constantine GD, Adachi JD, Bazedoxifene Study G (2012) Sustained efficacy and safety of bazedoxifene in preventing fractures in postmenopausal women with osteoporosis: results of a 5-year, randomized, placebo-controlled study. Osteoporos Int 23:351-363

17. Adami S, Palacios S, Rizzoli R, Levine AB, Sutradhar S, Chines AA (2014) The efficacy and safety of bazedoxifene in postmenopausal women by baseline kidney function status. Climacteric 17:273-284

18. Ishani A, Blackwell T, Jamal SA, Cummings SR, Ensrud KE, Investigators M (2008) The effect of raloxifene treatment in postmenopausal women with CKD. J Am Soc Nephrol 19:1430-1438

19. Horio M, Imai E, Yasuda Y, Watanabe T, Matsuo S, Collaborators Developing the Japanese Equation for Estimated GFR (2013) GFR estimation using standardized serum cystatin C in Japan. Am J Kidney Dis 61:197-203

20. Kenny AP, Glen AC (1973) Tests of phosphate reabsorption. Lancet 2:158 
21. Gao P, Scheibel S, D'Amour P, John MR, Rao SD, Schmidt-Gayk H, Cantor TL (2001) Development of a novel immunoradiometric assay exclusively for biologically active whole parathyroid hormone 1-84: implications for improvement of accurate assessment of parathyroid function. J Bone Miner Res 16:605-614

22. Genant HK, Jergas M, Palermo L, Nevitt M, Valentin RS, Black D, Cummings SR (1996) Comparison of semiquantitative visual and quantitative morphometric assessment of prevalent and incident vertebral fractures in osteoporosis The Study of Osteoporotic Fractures Research Group. J Bone Miner Res 11:984-996

23. Majima T, Komatsu Y, Shimatsu A, Satoh N, Fukao A, Ninomiya K, Matsumura T, Nakao K (2008) Efficacy of combined treatment with raloxifene and alfacalcidol on bone density and biochemical markers of bone turnover in postmenopausal osteoporosis. Endocr J 55:127-134

24. Gorai I, Hattori S, Tanaka Y, Iwaoki Y (2012) Alfacalcidol-supplemented raloxifene therapy has greater bone-sparing effect than raloxifene-alone therapy in postmenopausal Japanese women with osteoporosis or osteopenia. J Bone Miner Metab 30:349-358

25. Takeda S, Sakai S, Shiraishi A, Koike N, Mihara M, Endo K (2013) Combination treatment with eldecalcitol (ED-71) and raloxifene improves bone mechanical strength by suppressing bone turnover and increasing bone mineral density in ovariectomized rats. Bone 53:167-173

26. Melamed ML, Blackwell T, Neugarten J, Arnsten JH, Ensrud KE, Ishani A, Cummings SR, Silbiger SR (2011) Raloxifene, a selective estrogen receptor modulator, is renoprotective: a post-hoc analysis. Kidney Int 79:241-249

27. Hadjadj S, Gourdy P, Zaoui P, Guerci B, Roudaut N, Gautier JF, Chabin M, Mauco G, Ragot S, Group RS (2007) Effect of raloxifene -- a selective oestrogen receptor modulator -- on kidney function in post-menopausal women with Type 2 diabetes: results from a randomized, placebo-controlled pilot trial. Diabetic medicine : a journal of the British Diabetic Association 24:906-910

28. Nishi Y, Satoh M, Nagasu H, Kadoya H, Ihoriya C, Kidokoro K, Sasaki T, Kashihara N (2013) Selective estrogen receptor modulation attenuates proteinuria-induced renal tubular damage by modulating mitochondrial oxidative status. Kidney Int 83:662-673

29. Delle H, Rocha JR, Cavaglieri RC, Vieira JM, Jr., Malheiros DM, Noronha IL (2012) Antifibrotic effect of tamoxifen in a model of progressive renal disease. J Am Soc Nephrol 23:37-48

30. Imai E, Horio M, Yamagata K, Iseki K, Hara S, Ura N, Kiyohara Y, Makino H, 
Hishida A, Matsuo S (2008) Slower decline of glomerular filtration rate in the Japanese general population: a longitudinal 10-year follow-up study. Hypertens Res 31:433-441

31. Helmersson-Karlqvist J, Flodin M, Hansson LO, Larsson A (2013) The age related association is more pronounced for cystatin C estimated GFR than for creatinine estimated GFR in primary care patients. Clin Biochem 46:1761-1763

32. Uebelhart B, Herrmann F, Rizzoli R (2009) Effects of the SERM raloxifene on calcium and phosphate metabolism in healthy middle-aged men. Clin Cases Miner Bone Metab 6:163-168

33. Dick IM, Devine A, Beilby J, Prince RL (2005) Effects of endogenous estrogen on renal calcium and phosphate handling in elderly women. Am J Physiol Endocrinol Metab 288:E430-435

34. Uemura H, Irahara M, Yoneda N, Yasui T, Genjida K, Miyamoto KI, Aono T, Takeda E (2000) Close correlation between estrogen treatment and renal phosphate reabsorption capacity. J Clin Endocrinol Metab 85:1215-1219

35. KDIGO (2017) Kidney Disease: Improving Global Outcomes (KDIGO) CKD-MBD Update Work Group. KDIGO 2017 clinical practic guideline update for the diagnosis, evaluation, prevention, and treatment of chronic kidney disease-mineral and bone disorder (CKD-MBD). Kidney Int Suppl 7:1-59

36. Go AS, Chertow GM, Fan D, McCulloch CE, Hsu CY (2004) Chronic kidney disease and the risks of death, cardiovascular events, and hospitalization. N Engl J Med 351:1296-1305

37. Da J, Xie X, Wolf M, Disthabanchong S, Wang J, Zha Y, Lv J, Zhang L, Wang H (2015) Serum Phosphorus and Progression of CKD and Mortality: A Meta-analysis of Cohort Studies. Am J Kidney Dis 66:258-265 
Figure legends

Figure 1. Changes in LS-BMD after bazedoxifene treatment

Mean \pm SEM. The changes in LS-BMD were significant by one-way ANOVA $(P=$ 0.0195). $* P<0.05 v s$. baseline (Dunnett's test).

Figure 2. Changes in eGFRcys after bazedoxifene treatment

Mean \pm SEM. The changes in eGFRcys were significant by one-way ANOVA $(P=$ 0.0017). $* P<0.05 v s$. baseline (Dunnett's test).

Figure 3. Changes in serum phosphate concentration and TmP/GFR after bazedoxifene treatment

Mean \pm SEM. The changes in serum phosphate $(P=0.0033)$ and TmP/GFR $(P=0.0164)$ were significant by one-way ANOVA. ${ }^{*} P<0.05 v s$. baseline (Dunnett's test).

Figure 4. Changes in serum wPTH after bazedoxifene treatment

Mean \pm SEM. The changes in serum wPTH were significant by one-way ANOVA $(P=$ 0.0239). ${ }^{*} P<0.05$ vs. baseline (Dunnett's test). 
Figure 5. Changes in serum intact FGF23 after bazedoxifene treatment

Mean \pm SEM. The changes in serum intact FGF23 were significant by one-way ANOVA $(P=0.0198) . * P<0.05$ vs. baseline (Dunnett's test).

Figure 6. Relationships between the absolute reductions in eGFRcys ( $\Delta$ eGFRcys) and those in serum phosphate concentration ( $\Delta$ phosphate) between baseline and 3 months after bazedoxifene treatment $\Delta \mathrm{eGFR}$ cys showed a significant negative correlation with $\Delta$ phosphate $(\mathrm{r}=-0.287, P=$ 0.0479 , by simple regression). 
Table 1. Clinical characteristics of the participants

Characteristic $(n=48)$

Women/Men, n (\%)

$48(100) / 0(0)$

Age (years)

$71.2 \pm 8.5$

BMI $\left(\mathrm{kg} / \mathrm{m}^{2}\right)$

$21.0 \pm 2.3$

eGFR (mL/min/1.73 $\left.\mathrm{m}^{2}\right)$

$72.2 \pm 14.1$

$\mathrm{Ca}(\mathrm{mg} / \mathrm{dL})$

$9.3 \pm 0.3$

Phosphate (mg/dL)

$3.6 \pm 0.3$

Tmp/GFR (mg/dL)

$3.16 \pm 0.38$

wPTH $(\mathrm{pg} / \mathrm{mL})$

$20.0 \pm 6.0$

25OHD (ng/mL)

$26.3 \pm 8.6$

CTX (ng/mL)

$0.556 \pm 0.234$

LS-BMD $\left(\mathrm{g} / \mathrm{cm}^{2}\right)$

$0.684 \pm 0.076$

FN-BMD $\left(\mathrm{g} / \mathrm{cm}^{2}\right)$

$0.533 \pm 0.084$

TH-BMD $\left(\mathrm{g} / \mathrm{cm}^{2}\right)$

$0.632 \pm 0.086$

Vertebral fractures (yes/no)

$12 / 36$ 
Values are expressed as $\mathrm{n}(\%)$ or mean $\pm \mathrm{SD}$.

Abbreviations: BMI, body mass index; eGFR, estimated glomerular filtration rate; Ca, calcium; Tmp/GFR, ratio of the maximum tubular reabsorption rate of phosphate to the glomerular filtration rate; wPTH, whole parathyroid hormone concentration; 25OHD, 25-hydroxyvitamin D; LS-BMD, lumbar spine bone mineral density; FN-BMD, femoral neck bone mineral density; TH-BMD, total hip bone mineral density. 


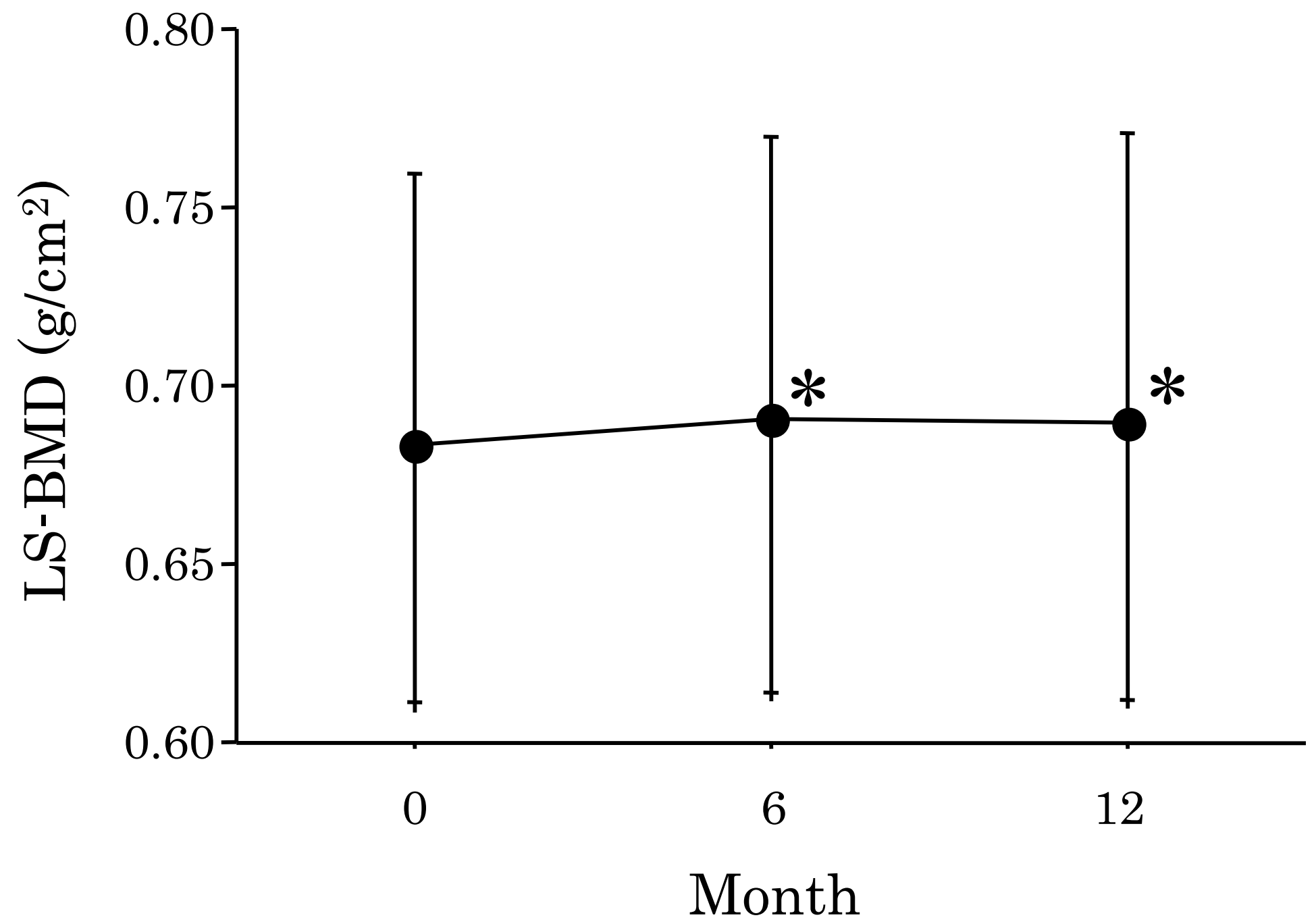

Fig. 1 


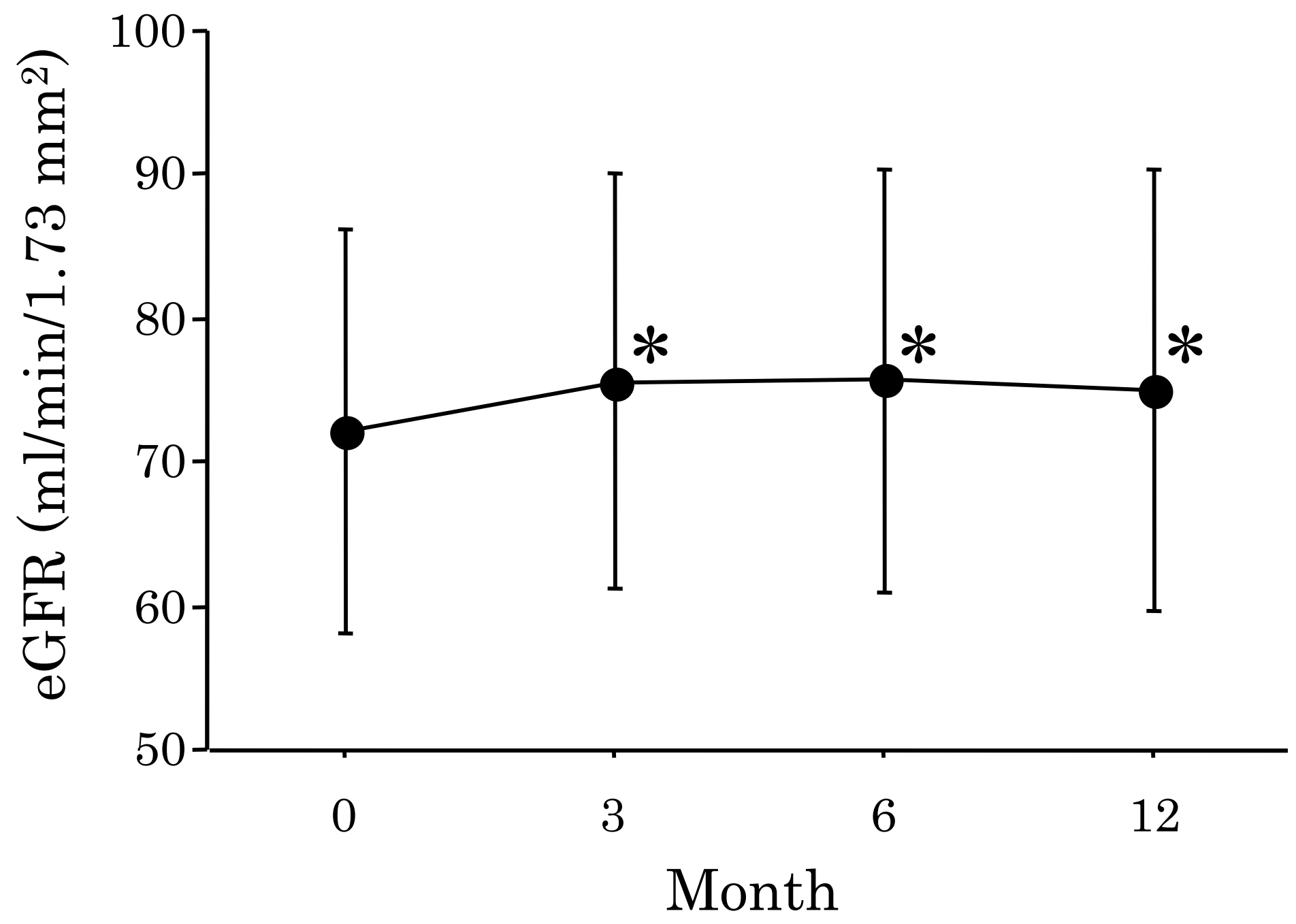

Fig. 2 


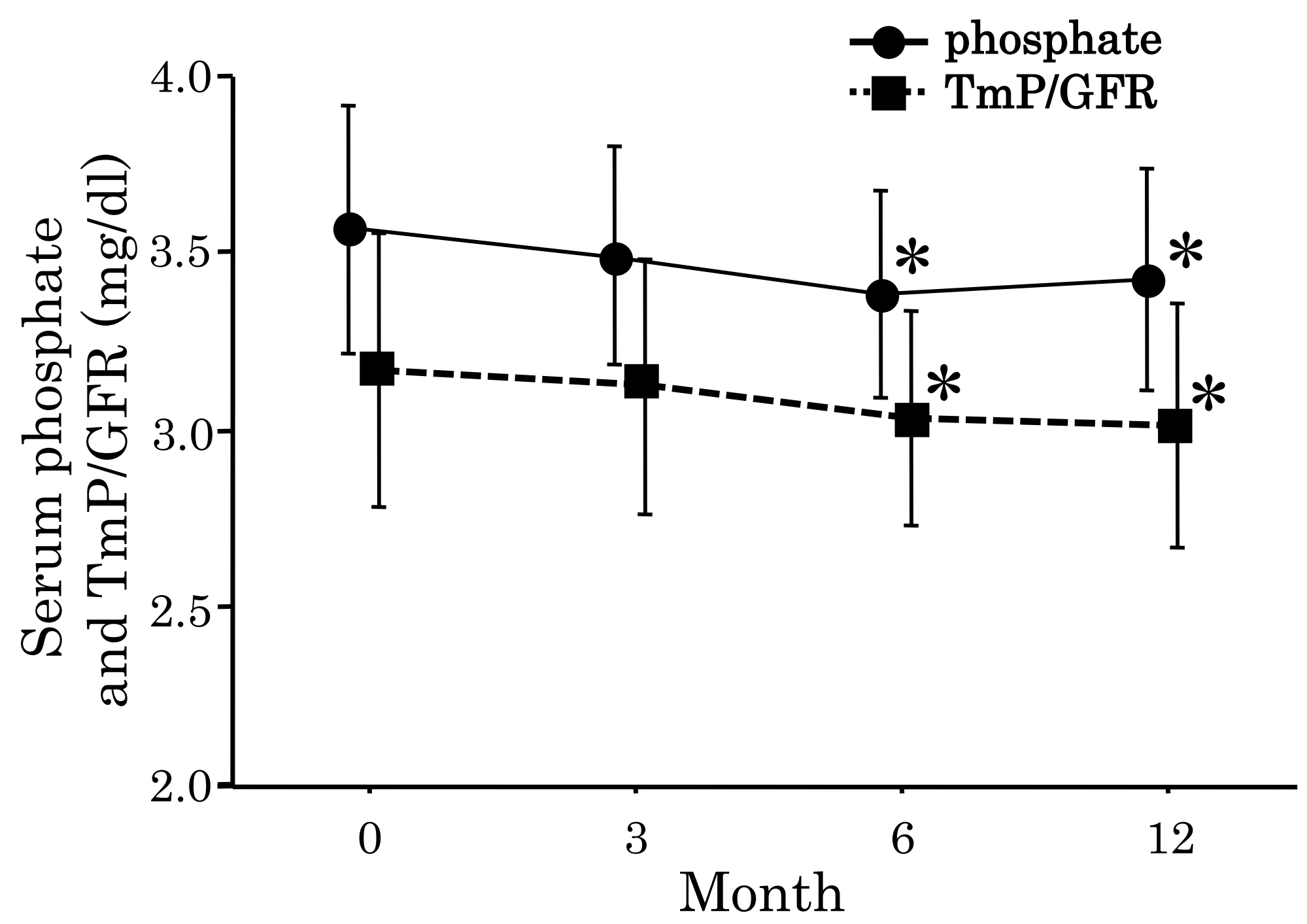

Fig. 3 


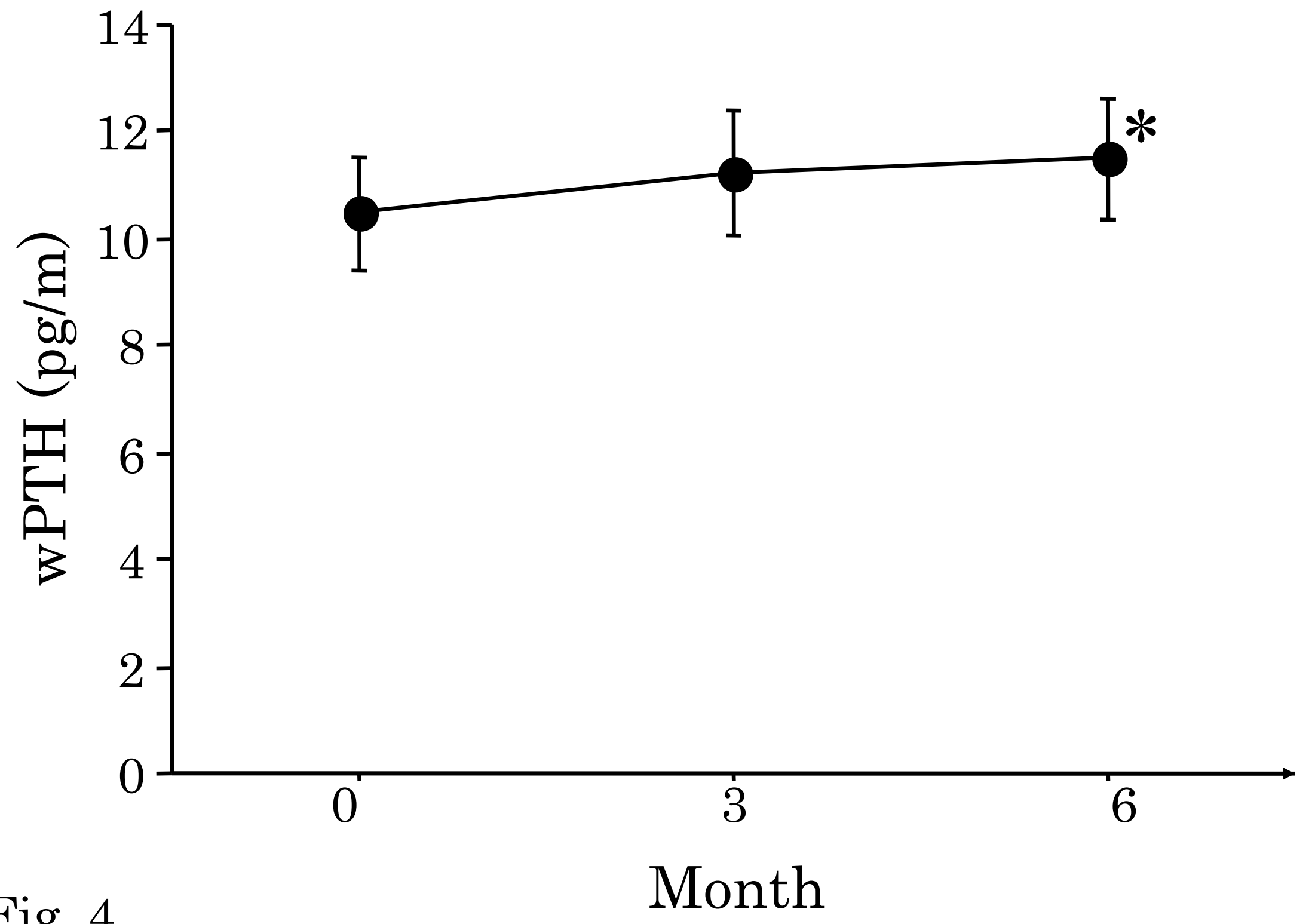

Fig. 4 


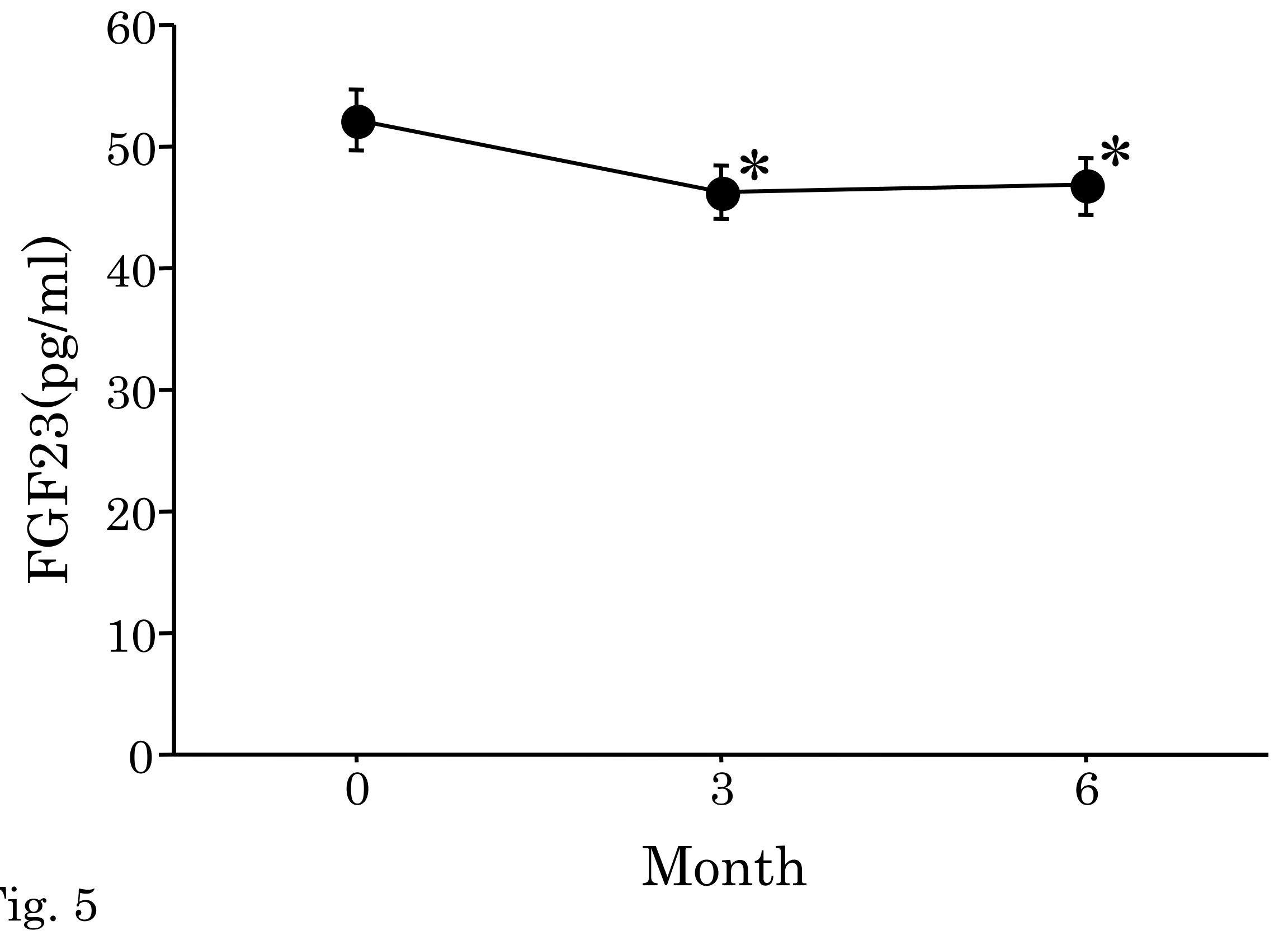




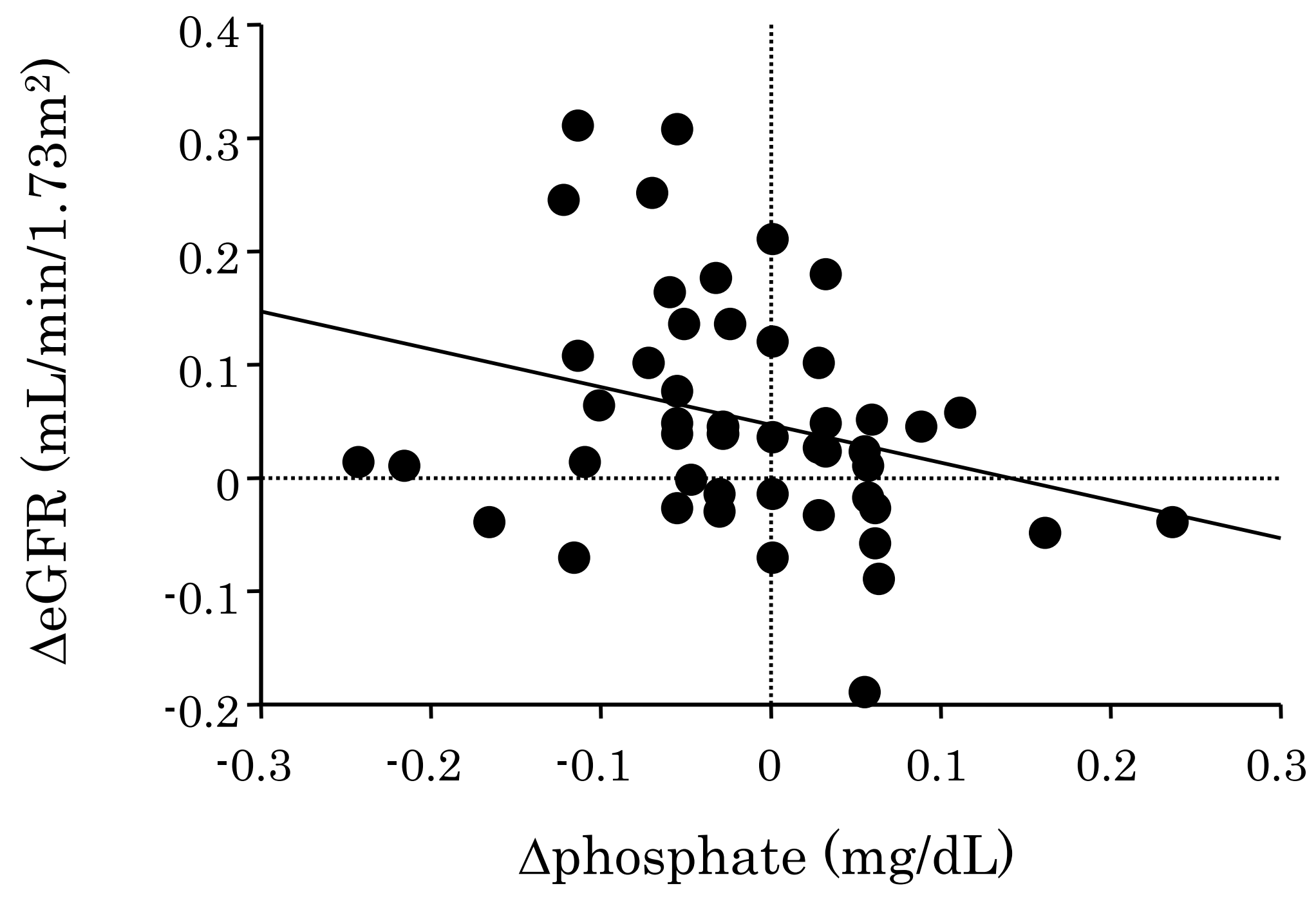

Fig. 6 